\title{
DIAGNÓSTICO AMBIENTAL: UMA PESQUISA EXPLORATÓRIA NA REGIÃO FRONTEIRA OESTE DO RIO GRANDE DO SUL
}

\author{
Cibele Martins, Thiago Beltrame, Suzy Elizabeth Pinheiro Canes, Andressa Rocha Lhamby, Victor \\ Kloeckner Pires, Alberto Souza Schmidt
}

http://dx.doi.org/10.5902/223613087594

\section{RESUMO}

Na área da Gestão Ambiental, a assessoria e consultoria ambiental destacam-se como segmentos bastante promissores. A demanda por este ramo de trabalho tem crescido devido à Legislação Ambiental Brasileira ser uma das mais bem elaboradas do mundo e pela rigorosa cobrança por parte dos órgãos ambientais, para que as empresas cumpram as exigências da lei. Através dos estudos constatou-se que ainda é pequeno o número de empresas que procuram por serviços de consultoria ou assessoria ambiental no município estudado. Observou-se no setor serviços um maior planejamento em relação às questões ambientais, sendo que muitas organizações inseriram-nas em seus orçamentos, buscando identificar oportunidades de reduzir os custos voltados ao meio ambiente. Ainda, quanto à atuação do gestor ambiental notou-se que existe uma resistência à incorporação de ações as quais minimizem os impactos causados por seus empreendimentos ao meio ambiente e uma falta de informação sobre os sistemas de gestão ambiental e a atuação dos profissionais da área.

Palavras-chave: Consultoria ambiental; Gestão Ambiental; Meio Ambiente

\begin{abstract}
In the area of environmental management, the environmental consulting and advisory services stand out as promising segments. The demand for this line of work has grown due to the Brazilian Environmental Legislation to have one of the most elaborate in the world and the rigorous control by environmental agencies, for companies to comply with the requirements of the law. The studies found that it is still a small number of companies looking for consulting or advisory services in the municipal studied. There was greater planning in relation to environmental issues, and many organizations consider the issues in their budgets and the service sector is one that seeks to identify further opportunities to reduce costs facing the environment. Still, as the performance of the environmental manager noted that there is a resistance to the incorporation of actions which minimize the impacts of its projects on the environment and the lack of information on environmental management systems and the performance of professionals.
\end{abstract}

Keywords: Environmental Consulting, Environmental Management, Environmental

\section{Introdução}

Nas últimas décadas verificou-se uma grande mudança na maneira como as empresas estão trabalhando. Além das preocupações com os processos de produção e tendências de mercado, as mesmas passaram a se preocupar também, com o impacto que causam ao meio ambiente e as suas consequências. Para Donaire (2009), a questão ambiental está se tornando 
MARTINS et al., v(11), no 11, p. 2389 - 2399, JAN-ABR 2013.

Monografias Ambientais

RENOMUESM

(e-ISSN: 2236-1308)

matéria obrigatória na agenda dos executivos das empresas. A globalização dos negócios, a internacionalização dos padrões de qualidade ambiental descritos na série ISO 14000, a conscientização crescente dos atuais consumidores e a disseminação da educação ambiental nas escolas permite antever que a exigência dos futuros consumidores em relação à preservação do meio ambiente e à qualidade de vida deverá se intensificar.

O número de empresas que não adotam práticas ambientalmente correta ainda é grande, mas as que a fizeram, vem se tornando referências em seus respectivos setores e caracterizandose como modelos a serem seguidos na busca pela excelência ambiental.

Além da comunidade e do mercado, outro fator externo, o Estado, pode levar a uma mudança das empresas no que diz respeito à questão ambiental e aos motivos que as levariam a adequar-se aos novos valores de respeito e conservação dos recursos naturais. É a legislação ambiental, juntamente com suas instituições e atividades de controle da contaminação, que são capazes, através de seus instrumentos, de proteger a saúde das pessoas e o bem comum.

Este trabalho possui como objetivo principal realizar uma pesquisa exploratória a fim de levantar informações a respeito do conhecimento/desconhecimento e interesse/desinteresse referente às questões envolvendo meio ambiente nas organizações, além de identificar o conhecimento/desconhecimento e aceitação do trabalho realizado por um gestor ambiental (consultoria e assessoria ambiental) por parte de algumas empresas da Região Fronteira Oeste do Estado do Rio Grande do Sul. Fez-se a pesquisa em 30 empresas, sendo estas divididas em setor industrial, comércio e serviços.

\section{Referencial Bibliográfico}

\subsection{Desenvolvimento Sustentável}

Pela declaração da Conferência das Nações Unidas sobre Meio Ambiente e Desenvolvimento, celebrada no Rio de Janeiro em 1992, desenvolvimento sustentável é uma estratégia que propõe um desenvolvimento que atenda às necessidades humanas do presente, e não prejudique o meio ambiente e as gerações futuras. Tem como finalidade o pleno desenvolvimento das capacidades efetivas e intelectuais de todo ser humano. Assim, qualidade de vida passa a ser o centro de todo e qualquer objetivo das políticas de desenvolvimento sustentável, mesmo considerando que o discurso de sustentabilidade admite várias interpretações, as quais dependem de diferentes interesses e estratégias. Para isso deve-se abandonar o conceito de qualidade de vida baseada no consumismo materialista de supérfluos, que acaba desviando a atenção das necessidades básicas, aquelas que deveriam ser promovidas pelas políticas do bem-estar do Estado para satisfazer as necessidades de caráter mais qualitativo.

Leff (2001), um dos mais influentes pesquisadores da temática, prega uma qualidade de vida estabelecida através de um processo de (re)apropriação das condições do viver da população em relação às suas necessidades e seus valores subjetivos. Os valores culturais passariam a intervir como mediadores na busca destas necessidades. Assim, a qualidade de vida se converteria no valor fundamental que orientaria o desenvolvimento de cada comunidade e o projeto de vida de cada pessoa.

De acordo com Teixeira e Bessa (2009), a demora das organizações brasileiras em internalizar o conceito de desenvolvimento sustentável deve-se a diversos fatores. Um deles é o fato de as trajetórias seguidas pelas empresas de diferentes setores distinguirem 
MARTINS et al., v(11), no 11, p. 2389 - 2399, JAN-ABR 2013.

Monografias Ambientais

RENOAMESY

(e-ISSN: 2236-1308)

significativamente. Isso se deve também à concepção, que predominou durante décadas, de que a preservação do meio ambiente e o lucro eram antagônicos. Essa concepção se refletiu nas organizações de todos os portes e setores. Refutar essa visão tem sido um processo lento, tendose chegado, em alguns países, na incorporação da visão de stakeholders nas novas estratégias de desenvolvimento.

É necessária uma mudança de hábitos de consumo e modos de vida, para que se alcance efetivamente a sustentabilidade. Mas, possivelmente, esta mudança dependerá mais do setor produtivo do que dos consumidores, pois são os primeiros que poderão trazer para o mercado propostas de produtos e serviços ambientalmente mais sustentáveis.

\subsection{A Legislação Ambiental Brasileira}

De acordo com Valle (2002), até o início da década de 1970, não existia no Brasil uma legislação específica que abordasse o tema ambiental. Algumas normas e regulamentos que tratavam da saúde pública, da proteção à fauna e à flora e da segurança e higiene industrial era tudo que se podia reunir com relação ao assunto. Atualmente, essa legislação existe e, deve-se reconhecer, é bastante completa, abrangente e avançada.

É considerada uma das mais bem elaboradas e completas do mundo, graças principalmente aos decretos, às leis e aos regulamentos que foram emitidos a partir de 1981. Existe um conjunto de leis que definem obrigações, responsabilidades e atribuições, tanto dos empreendedores quanto do Poder Público, nas várias esferas: federal, estadual e municipal. Além das leis, há uma série de regulamentos a serem cumpridos, elaborados por órgãos como o CONAMA (os órgãos colegiados normalmente emitem "Resoluções" e "Deliberações"), Ministério do Meio Ambiente e Secretarias Estaduais e Municipais do Meio Ambiente. O Poder Executivo emite os "Decretos", os ministros e secretários emitem "Portarias", havendo nesse caso uma subordinação. Os atos de uma determinada autoridade não podem ser conflitantes com os atos de seus superiores. A União tem a responsabilidade de fixar as leis de caráter geral, complementadas por leis mais específicas dos Estados e Municípios (MOURA, 2008).

A Lei da Política Nacional do Meio Ambiente (6.938/81) e a Constituição Federal de 1988 (artigo 225) exigem a realização de estudos de impacto ambiental e o licenciamento de atividades potencialmente perigosas, requerendo-se essa licença no órgão ambiental federal (IBAMA), estadual (SMA) ou municipal, conforme o caso. Uma série grande de empreendimentos requer essa licença para que possam ser construídos e operados (MOURA, 2008).

A Resolução CONAMA 001/86 de 26.1.1986, no seu artigo 4으, estabelece que:

Os órgãos setoriais (nível estadual) do SISNAMA (Sistema Nacional do Meio Ambiente) deverão compatibilizar os processos de licenciamento com as etapas de planejamento e implantação das atividades modificadoras do ambiente.

\subsection{O Desempenho Ambiental das Empresas Brasileiras}

Quanto ao desempenho ambiental das empresas no Brasil, Moura (2008) separa as empresas em quatro categorias:

a) As que nada fazem em relação ao meio ambiente, já que suas atividades geram poucos impactos;

http://cascavel.ufsm.br/revistas/ojs-2.2.2/index.php/remoa 
MARTINS et al., v(11), no 11, p. 2389 - 2399, JAN-ABR 2013.

Monografias Ambientais

RENOANFS

(e-ISSN: 2236-1308)

b) As que pouco atuam, apesar de gerarem impactos, limitando-se a tentar cumprir os padrões mínimos da legislação;

c) As que procuram ter uma atuação mais significativa, possuindo uma área dedicada a tratar das questões ambientais da empresa e seguem quase sempre, os padrões corporativos;

d) As que estão procurando obter certificação, segundo normas ambientais, para o seu sistema de gestão ambiental (ISO 14001).

$\mathrm{O}$ autor ressalta ainda que, algumas empresas se enquadram na situação $\underline{\mathrm{c}}$ possuem um excelente desempenho ambiental, sem que tenham a necessidade de passar para a situação $\underline{\mathrm{d}}$.

Com a disseminação dos conceitos de Garantia de Qualidade e Responsabilidade Social, a Gestão Ambiental passou a ocupar, conforme Valle (2002), uma posição de destaque entre essas funções organizacionais, não somente pela contribuição positiva que agrega à imagem da empresa, mas também, pelos efeitos danosos que um mau desempenho ambiental pode causar a essa imagem. Em consequência disso, a qualidade ambiental tornou-se parte dos valores cultivados pela organização e desempenha, portanto, um papel importante na estruturação e manutenção de sua imagem.

\subsection{Consultoria e Assessoria Empresarial}

A consultoria empresarial é um processo interativo de um agente de mudanças externo à empresa, o qual assume a responsabilidade de auxiliar os executivos e profissionais da referida empresa nas tomadas de decisões, não tendo, entretanto, o controle direto da situação (OLIVEIRA, 2009). O agente de mudanças é o profissional que possui a capacidade de desenvolver comportamentos, atitudes e processos que possibilitem a empresa fazer transações de maneira proativa e interativamente com os diversos fatores do ambiente empresarial. De acordo com Crocco e Guttmann (2005) o setor de consultoria cresceu mundialmente e em taxas significativas, criando empresas e empregos, originando associações setoriais, estruturando-se, enfim. Esse crescimento não foi obra do acaso. Resultados de levantamentos e pesquisas apontaram para uma gama de motivos que levaram as organizações - empresas, associações, órgãos governamentais, institutos e fundações - a contratar consultores.

Conforme Oliveira (2009), a assessoria empresarial, por teoria, trata-se da atividade sistemática de auxiliar a empresa- cliente ou o responsável de uma unidade organizacional em assuntos gerais ou específicos. Ela possui, portanto, uma abordagem mais ampla do que a consultoria empresarial. Isto pode acarretar em algumas dúvidas a respeito da diferença entre esses dois processos, mas, na verdade, uma atividade não exclui a outra. Enquanto na consultoria empresarial as atividades são mais voltadas no auxílio ao desenvolvimento de uma idéia, na elaboração de uma solução ou ainda encaminhar um processo ou situação que envolva o "pensar".

\subsection{Gestão Ambiental formando Consultores/Assessores Ambientais}

A gestão ambiental consiste em um conjunto de medidas e procedimentos bem definidos que, se adequadamente aplicados, permitem reduzir e controlar os impactos introduzidos por um empreendimento sobre o meio ambiente. O ciclo de atuação da gestão ambiental, para que esta seja eficaz, deve cobrir desde a fase de concepção do projeto até a eliminação efetiva dos resíduos 
gerados pelo empreendimento depois de implantado e durante todo o período de seu funcionamento (VALLE, 2002). Ainda segundo o autor, a gestão ambiental requer, como premissa fundamental, um comprometimento da alta administração da organização em definir uma política ambiental clara e objetiva, que norteie as atividades da organização em relação ao meio ambiente e que seja apropriada à finalidade, à escala da organização e aos impactos ambientais de suas atividades, produtos ou serviços. Ressalta-se, ainda, que a gestão ambiental pode ser muito abrangente, sendo utilizada frequentemente para designar ações ambientais em determinados espaços geográficos (FARIAS et al., 2010).

$\mathrm{Na}$ visão de Dias (2009), a gestão ambiental está adquirindo posição de destaque em termos de competitividade, devido aos benefícios que traz ao processo produtivo como um todo. Os estímulos para se adotar métodos de gestão ambiental vão muito além dos interesses econômicos. É possível demonstrar aos empresários que adotando ferramentas do sistema de gestão ambiental nos seus negócios, a redução dos custos da empresa pode ser imediata, assim como a melhora da imagem da empresa e do seu produto perante seus clientes, e também a inovação tecnológica que a organização pode oferecer, conferindo à empresa vantagens competitivas no mercado. Portanto, p gestor ambiental é o profissional que elabora e executa projetos de gestão ambiental que visem à preservação dos recursos naturais aliado ao progresso, ou seja, ele é considerado o administrador do meio ambiente (BRASIL PROFISSÕES, 2012). Para a formação de um gestor ambiental é essencial visão holística, saber trabalhar com a interdisciplinaridade, com a capacidade de observação, sensibilidade, dinamismo, determinação e metodologia. Tendo em vista que um consultor/assessor vive de seu patrimônio cultural e da aplicação de seu conhecimento, tais competências serão importantes para aqueles que tiverem interesse em se aventurar por este campo de atuação. O profissional deve ser valorizado pelo segmento de mercado escolhido (no caso o ambiental) e também se especializar para estar preparado para oferecer serviços que sejam superiores aos existentes no mercado.

\section{Metodologia}

Para a concepção deste trabalho realizou-se uma pesquisa exploratória, a qual para Gil (2010) possui como propósito proporcionar uma familiaridade com um problema e há uma tendência de seu planejamento ser bastante flexível, pois interessa considerar os mais variados aspectos relativos ao fato ou fenômeno estudado. Ainda, LAKATOS e MARCONI (2010) diz que através desta pesquisa obtêm-se, na maioria das vezes, descrições qualitativas e quantitativas do objeto de estudo Para o levantamento de dados, selecionou-se uma amostra de trinta empresas da Região Fronteira oeste do RS, a fim de obter-se informações em relação às questões ambientais voltadas a gestão ambiental, e ainda, verificar o interesse dos gestores ou representantes nos serviços prestados por um gestor ambiental. As empresas foram escolhidas de modo que contemplasse todos os segmentos empresariais. Foram entrevistadas 7 empresas do setor da indústria, 13 empresas do setor de comércio e 10 do setor de prestação de serviços. Utilizou-se um questionário com questões fechadas que foi elaborado com base no Manual de Auditoria Ambiental (D'AVIGNON et al., 2001). 


\section{Resultados e discussões}

Com base nos levantamentos realizados, observou-se que a assessoria ambiental é um dos principais serviços solicitados aos profissionais ambientais. Ainda, averiguou-se que há muita procura por serviços envolvendo licenciamento ambiental. A Figura 1 mostra que a totalidade das indústrias que procuram consultoria ou assessoria ambiental são movidas por exigências de órgãos ambientais. As empresas prestadoras de serviços buscam auxílio. Predominantemente, em função da ação de órgãos fiscalizadores. Diferenciando-se dos outros setores, o ramo comercial move-se em busca de consultoria/assessoria com o propósito de melhorar a imagem ambiental da empresa perante a sociedade. Foi no setor de serviços que a contribuição com a preservação dos recursos naturais obteve maior percentual (Figura 1).

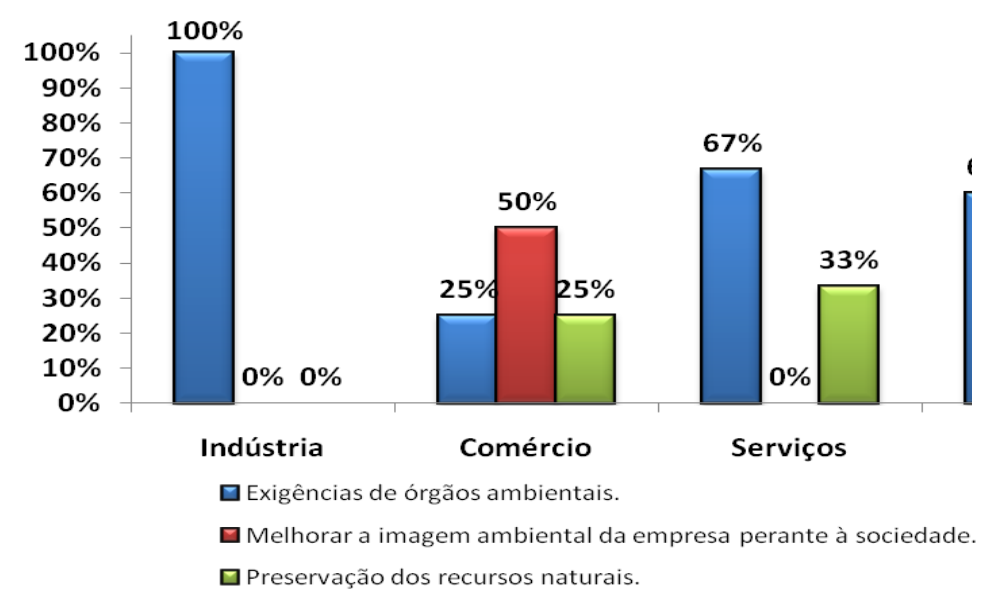

Figura 1: Razão o qual busca consultoria/assessoria ambiental.

Referente ao questionamento quanto à empresa possuir uma política ambiental definida em seu planejamento nota-se (Figura 2) que no setor da indústria, 57,1\% das empresas respondeu que possui definida esta política. Nos setores de comércio e prestação de serviços, este percentual é mais baixo, devido ao fato de não serem considerados poluidores em potencial, pois a geração de resíduos é menor.

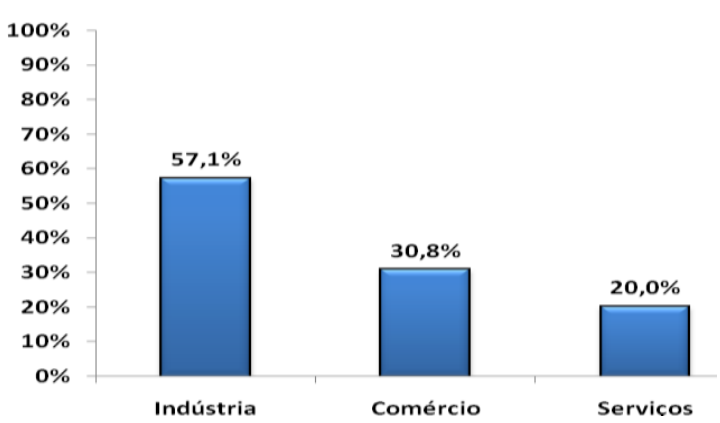

Figura 2: Percentual de empresas que possuem Política Ambiental Definida.

Constatou-se que o setor industrial (Figura 3) foi o que mais solicitou serviços de consultoria/assessoria ambiental (42,8\%). Esse fato deve-se a maior geração de resíduos e fiscalização. 
MARTINS et al., v(11), no 11, p. 2389 - 2399, JAN-ABR 2013.

Monografias Ambientais

RENOAUFSW

(e-ISSN: 2236-1308)

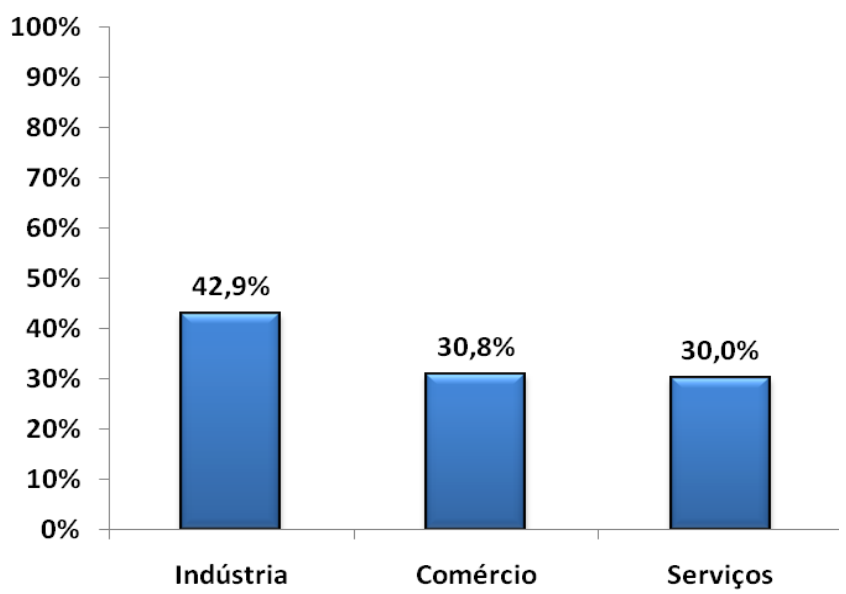

Figura 3: Percentual de empresas que já procuraram assessoria ou consultoria ambiental.

A totalidade das indústrias que procuram consultoria ou assessoria ambiental são movidas por exigências de órgãos ambientais. O ramo comercial solicita este tipo de serviço com o propósito de melhorar a imagem ambiental da empresa perante a sociedade. Verificou-se que o setor de serviços foi aquele em que a contribuição com a preservação dos recursos naturais obteve maior percentual.

Com relação ao recebimento de multas e advertências de órgãos ambientais, notase através da Figura 4, novamente, uma discrepância entre o setor industrial e os demais, embora os prestadores de serviço tenham apresentado percentual considerável. Percebeu-se que o setor de prestação de serviços sofre com a desinformação, pois alguns empresários não possuem o conhecimento necessário na área ambiental, como por exemplo, desconhecem a necessidade de licenciamento ambiental para que possam atuar.

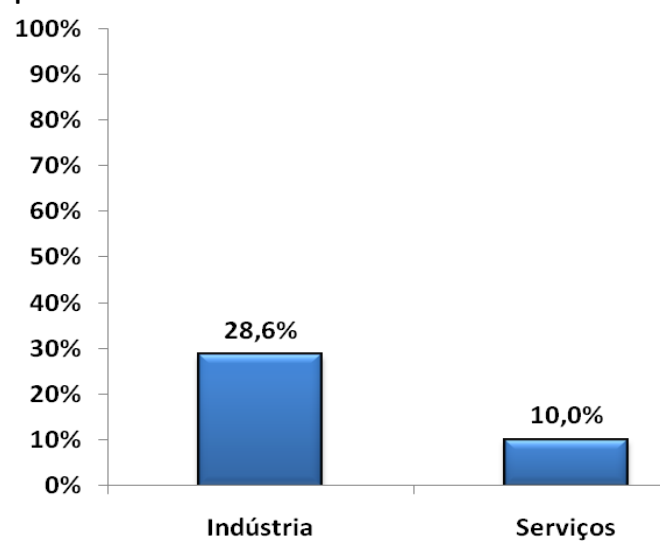

Figura 4: Percentual de empresas que já receberam multa ou advertência de algum órgão ambiental.

Referente a reclamações da comunidade sobre a atuação das empresas em relação ao meio ambiente (Figura 5), percebe-se que somente no setor da indústria houve um maior número de reclamações. O alto percentual (42,9\%), deve-se ao fato da indústria possuir máquinas e equipamentos que, além da geração de resíduos particulados (poeira, por exemplo), gera, ainda, a poluição sonora. 


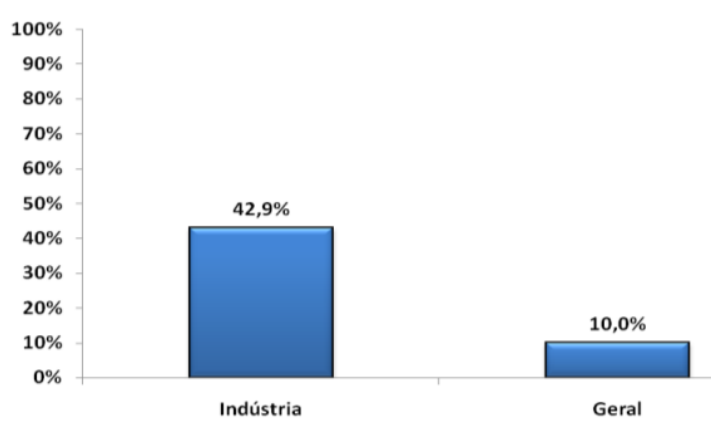

Figura 5: Percentual de empresas que já receberam reclamações da vizinhança de caráter ambiental.

A Figura 6 mostra que os setores industriais e de serviços apresentaram valores próximos, quanto aos gastos com as questões ambientais estão previstos. Algumas empresas do setor industrial e de serviços admitem que a questão ambiental está longe de ser uma de suas maiores preocupações. Verifica-se que o setor de prestação de serviços apresentou $90 \%$ de respostas positivas quando questionadas a respeito da identificação oportunidades de reduzir os custos ambientais, via reciclagem, conservação de energia, por exemplo. As maiores economias realizadas, conforme a pesquisa pôde revelar, são as referentes à energia elétrica e a utilização de água.

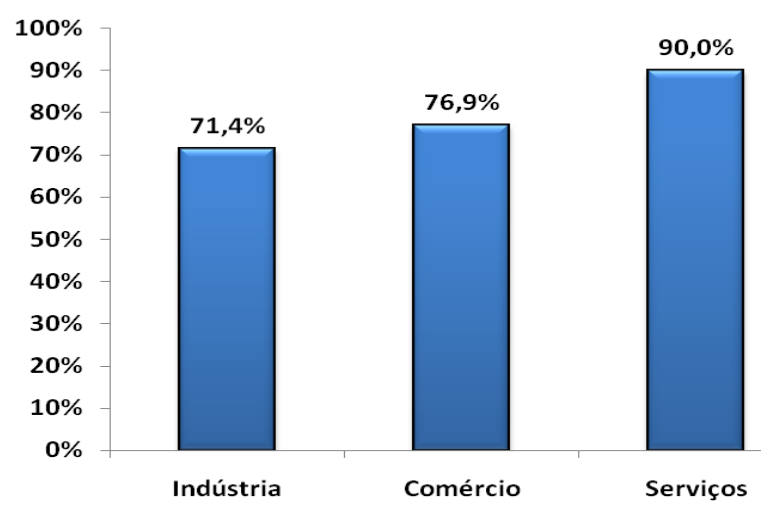

Figura 6: Percentual de empresas que procuram identificar oportunidades de reduzir os custos ambientais.

Questionou-se o conhecimento dos responsáveis pelas empresas em relação ao trabalho desenvolvido por um profissional de gestão ambiental e conforme demonstra a Figura 7 o setor industrial apresentou o menor percentual $(57,1 \%)$ em relação ao setor de comércio $(69,2 \%)$ e de serviços (90\%). Este resultado pode ser atribuído a dois fatores: o primeiro deles é que a região do município estudado não possui um grande número de indústrias e as existentes encontram-se distantes do universo acadêmico. Nos demais setores (comércio e serviços), já existe uma maior participação da comunidade universitária. 


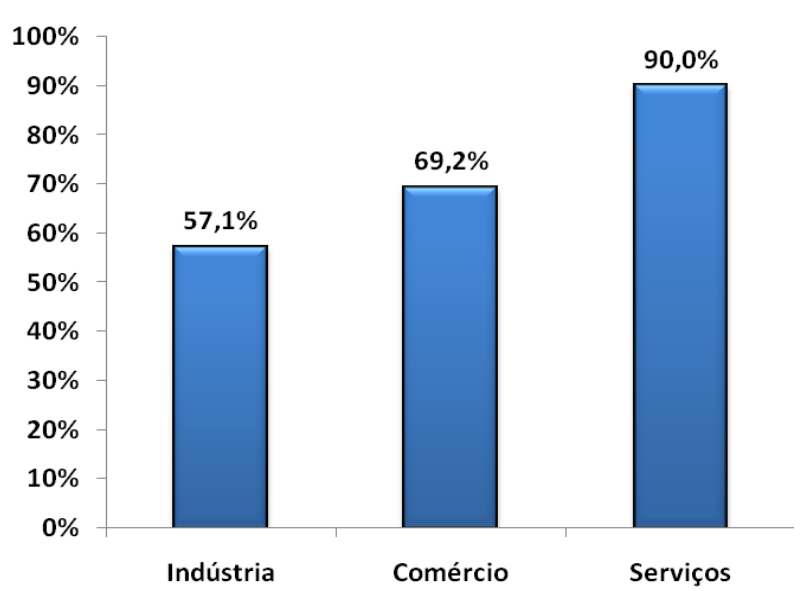

Figura 7: Empresas que conhecem o trabalho desenvolvido por um profissional de gestão ambiental.

Como mostrado na Figura 8, embora a indústria tenha apresentado o menor percentual em relação ao conhecimento do trabalho desenvolvido por esse profissional, este setor demonstra que seria o que mais contrataria este colaborador, com totalidade de $100 \%$. Os entrevistados dos demais setores (comércio e serviços) indagaram que somente contratariam esse profissional para realizar trabalhos eventuais (assessoria ou consultoria ambiental, por exemplo), dificilmente para efetivo da empresa.

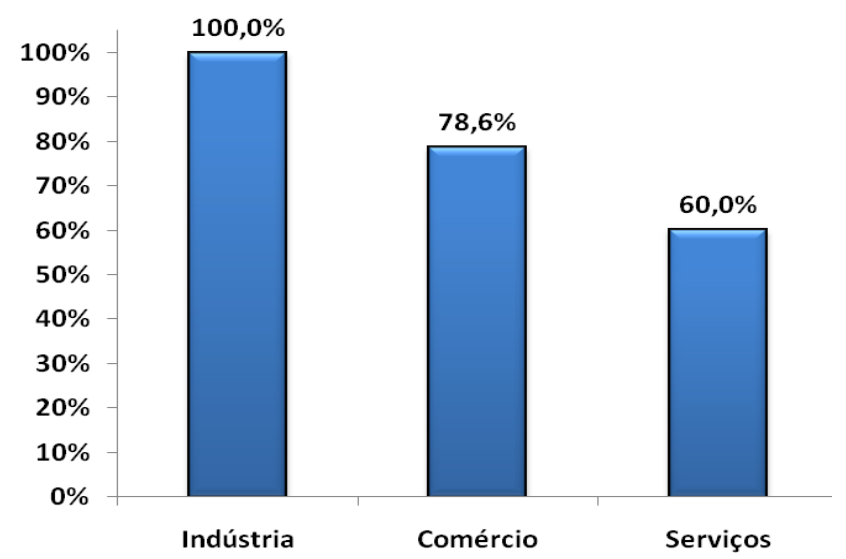

Figura 8: Empresas que contratariam um profissional da área de gestão ambiental.

\section{Considerações finais}

Após o estudo realizado, notou-se que o licenciamento ambiental é o processo mais visado pelas empresas pesquisadas, e principalmente a licença de operação para regularização, ou seja, aquela em que a empresa já está operando. Verificou-se que, em algumas vezes, a procura pelo serviço de assessoria só acontece a partir de uma advertência ou a pedido do Ministério Público. De uma maneira geral, os empreendimentos do município e região pesquisada, não se mostram comprometidos com a questão da preservação dos recursos naturais, mas somente com a validação de seus processos.

Verificou-se que a maioria das empresas não possui uma política ambiental definida, foi possível identificar que no setor industrial, a procura por algum tipo de serviço de assessoria ou 
MARTINS et al., v(11), no 11, p. 2389 - 2399, JAN-ABR 2013.

Monografias Ambientais

RENOAMFSW

(e-ISSN: 2236-1308)

consultoria ambiental é maior, devido - principalmente - pela exigência dos órgãos ambientais. $O$ setor comercial foi o que demonstrou maior preocupação com sua imagem perante a sociedade. Dentre o setor industrial e de serviços, observou-se maior planejamento em relação às questões ambientais, sendo que muitas organizações já consideram estas questões em seus orçamentos. As empresas se mostraram dispostas a reduzirem seus custos ambientais via reciclagem e conservação de energia, mas no geral não apresentaram métodos muito inovadores.

Quanto às questões relacionadas ao profissional da gestão ambiental, observou-se grande desconhecimento da importância do trabalho que pode ser realizado por ele dentro das organizações, entretanto, a pesquisa revelou que em geral, entre os três setores envolvidos, um percentual de $80 \%$ das empresas contrataria este profissional. Logo, percebe-se que seria importante informar a sociedade em relação a esta profissão e a importância que um gestor ambiental possui no organograma de uma instituição.

\section{Referências Bibliográficas}

ALMEIDA, F. Os Desafios da Sustentabilidade uma ruptura urgente. 3. ed. Rio de Janeiro: Elsevier Campus, 2007.

BRASIL, LEI № 6.938, de 31 de Agosto de 1981. Dispõe sobre a Política Nacional do Meio Ambiente, seus fins e mecanismos de formulação e aplicação e dá outras providências.

BRASIL. Ministério do Meio Ambiente, Conselho Nacional do Meio Ambiente (CONAMA). Resolução №001/86, de 23 de Janeiro de 1986. Considera-se impacto ambiental qualquer alteração das propriedades físicas, químicas e biológicas do meio ambiente, causada por qualquer forma de matéria ou energia resultante das atividades humanas.

BRASIL PROFISSÕES. Gestor ambiental. Disponível em: http://www.brasilprofissoes.com.br/profissoes/gestorambiental. Acessado em 10 de Setembro de 2012.

CROCCO, L., GUTTMANN, E. Consultoria Empresarial. São Paulo: Saraiva, 2005.

Declaração do Rio sobre Meio Ambiente e Desenvolvimento. Disponível em: http://www.mma.gov.br/port/sdi/ea/documentos/convs/decl_rio92.pdf. Acessado em 02 de Setembro de 2012.

DIAS, R. Gestão Ambiental: Responsabilidade Social e Sustentabilidade. São Paulo: Atlas, 2009.

DONAIRE, Denis. Gestão Ambiental na Empresa. 2. ed. São Paulo: Atlas, 2009.

FARIAS, L.G.Q, GÓES, A.O.S. JÚNIOR, A.C.S. Gestão ambiental e tecnologias ambientais: Práticas e benefícios em uma indústria alimentícia no Sul da Bahia. RGSA - Revista de Gestão Social e Ambiental. V.4, №.1, p. 80-911, 2010.

GIL, Antônio Carlos. Como elaborar projetos de pesquisa. São Paulo, 5a edição, 2010. Editora Atlas.

LA ROVERE, E. L.; D'AVIGNON, A.; PIERRE, C. V.; KLIGERMAN, D. C.; SILVA, H. V. O.; BARATA, M. M. L.; MALHEIROS, T. M. M. Manual de auditoria ambiental. 2. ed. Rio de Janeiro: Qualitymark, 2001.

LEFF, E. Saber Ambiental- Sustentabilidade, Racionalidade, Complexidade, Poder. Petróplis-RJ: Vozes/ PNUMA, 2001, $343 \mathrm{p}$.

MARCONI,M.A., LAKATOS, E.M. Fundamentos de metodologia cientifica. 7. Ed., São Paulo: Atlas, 2010.

MOURA, L. A. A. Qualidade e Gestão Ambiental. 5. ed. São Paulo: Juarez de Oliveira, 2008.

OLIVEIRA, D. P. R. Manual de Consultoria Empresarial: conceitos, metodologia, práticas. 8. ed. São Paulo: Atlas, 2009.

PHILIPPI JR., A., ROMÉRO, M. A., BRUNA, G. C. Uma Introdução à Gestão Ambiental. In: PHILIPPI JR., A., ROMÉRO, M.

A., BRUNA, G. C. Curso de Gestão Ambiental. Barueri, SP: Manole, 2004. 
MARTINS et al., v(11), no 11, p. 2389 - 2399, JAN-ABR 2013.

Monografias Ambientais

RENOANES

(e-ISSN: 2236-1308)

TEIXEIRA, M. G. C.; BESSA, E. S. Estratégias para Compatibilizar Desenvolvimento Econômico e Gestão Ambiental numa Atividade Produtiva Local. RAC, v. 13, edição especial, p. 1-18, 2009. Disponível em: http://www.anpad.org.br/rac

VALLE, C. E. Qualidade Ambiental: ISO 14000. 8. ed. São Paulo: Senac, 2002.

World Business Council for Sustainable Development. Disponível em:

http://www.wbcsd.org/templates/TemplateWBCSD5/layout.asp?MenuID=1. Acessado em 05 de Setembro de 2012. 